Pesq. Vet. Bras. 28(4):223-230, abril 2008

\title{
Causas de morte e razões para eutanásia de cães da Mesorregião do Centro Ocidental Rio-Grandense $(1965-2004)^{1}$
}

\author{
Rafael A. Fighera ${ }^{2}$, Tatiana M. Souza ${ }^{2}$, Marcia C. Silva², Juliana S. Brum³ ${ }^{3}$, \\ Dominguita L. Graça ${ }^{4}$, Glaucia D. Kommers ${ }^{4}$, Luiz F. Irigoyen ${ }^{4}$ e Claudio S.L. \\ Barros $^{4}$
}

\begin{abstract}
Fighera R.A., Souza T.M., Silva M.C., Brum J.S., Graça D.L., Kommers G.D., Irigoyen L.F. \& Barros C.S.L. 2008. [Causes of death and reasons for euthanasia in dogs from the midland region of the Midwest of Rio Grande do Sul State, Brazil (1965-2004).] Causas de morte e razões para eutanásia de cães da Mesorregião do Centro Ocidental Rio-Grandense (1965-2004). Pesquisa Veterinária Brasileira 28(4):223230. Departamento de Patologia, Universidade Federal de Santa Maria, 97105-900 Santa Maria, RS, Brazil. E-mail: anemiaveterinaria@yahoo.com.br

The main objective of this study was to investigate the prevalence of diseases culminating with death or motivating euthanasia of dogs from the midland region of the Midwest of Rio Grande do Sul State, Brazil. The necropsy files of the Laboratório de Patologia Veterinária (LPV) of the Universidade Federal de Santa Maria (UFSM) were accessed and necropsy protocols of dogs necropsied between January 1965 and December 2004 were reviewed. During this period 4,844 reports of canine necropsies were filed at the LPV-UFSM. The case distribution in relation to the disease categories diagnosed was as follows: infectious and parasitic diseases (1,693 [35.0\%]); neoplasms (378 [7.8\%]); disorders caused by physical agents (369 [7.6\%]); degenerative diseases (342 [7.1\%]); poisonings and toxinfections (112 [2.3\%]); euthanasia due to convenience (101 [2.1\%]); metabolic and endocrinological diseases (97 [2.0\%]); iatrogenic disorders (83 [1.7\%]); developmental disorders (25 [0.5\%]); immune mediate diseases (10 [0.2\%]); and nutritional disorders (6 $[0.1 \%])$. Other disorders, including multifactorial or idiopathic diseases contributed $80(1.6 \%)$ cases. In $1,548(32.0 \%)$ out of the 4,844 cases it was not possible to establish either cause of death or reason for euthanasia. Infectious and parasitic diseases (mainly canine distemper, parvoviral enteritis and intestinal parasitism), neoplasia (mainly mammary neoplasms and lymphoma), disorders caused by physical agents (mainly accidents caused by automotive vehicles) and degenerative diseases (mainly chronic renal failure, cirrhosis, and congestive heart failure) were the main disease categories causing death or motivating euthanasia in dogs of this midland region. However, when cases were evaluated in relation with the age of the dog, the disease prevalence differed. The main causes of death in puppies were infectious and parasitic disease (mainly parvoviral enteritis, canine distemper, and intestinal parasitism). In adult dogs the most important causes of death were canine distemper, neoplasia and trauma. In age dogs, approximately half of the deaths could be attributed to neoplasia and degenerative disease.
\end{abstract}

INDEX TERMS: Diseases of dogs, causes of death, reasons for euthanasia.

\footnotetext{
${ }^{1}$ Recebido em 4 de abril 2008.

Aceito para publicação em 14 de abril de 2008.

Parte da Tese de Doutorado do primeiro autor.

${ }^{2}$ Programa de Pós-Graduação em Medicina Veterinária, área de concentração em Patologia Veterinária, Centro de Ciências Rurais, Universi-
}

\footnotetext{
dade Federal de Santa Maria (UFSM), Camobi, Santa Maria, RS 97105900, Brasil. *Autor para correspondência: anemiaveterinaria@yahoo.com.br ${ }^{3}$ Bolsista de Iniciação Científica do CNPq junto ao Departamento de Patologia da UFSM.

${ }^{4}$ Departamento de Patologia, UFSM, Santa Maria, RS.
} 
RESUMO.- Este estudo teve como objetivo principal determinar a prevalência das doenças que culminam em morte ou que fazem com que os cães da Mesorregião do Centro Ocidental Rio-Grandense sejam submetidos à eutanásia. Para isso, foram revisados todos os protocolos de necropsia de cães, arquivados no Laboratório de Patologia Veterinária (LPV) da Universidade Federal de Santa Maria (UFSM), realizadas entre janeiro de 1965 e dezembro de 2004. Nos arquivos do LPV-UFSM foram encontrados 4.844 protocolos de necropsia de cães. A distribuição dos casos em relação às categorias de doenças diagnosticadas foi a seguinte: doenças infecciosas e parasitárias (1.693 [35,0\%]), neoplasmas $(378[7,8 \%])$, distúrbios causados por agentes físicos (369 [7,6\%]), doenças degenerativas $(342[7,1 \%])$, intoxicações e toxiinfecções (112 [2,3\%]), eutanásia por conveniência (101 [2,1\%]), doenças metabólicas e endocrinológicas (97 [2,0\%]), distúrbios iatrogênicos (83 [1,7\%]), distúrbios do desenvolvimento (25 [0,5\%]), doenças imunomediadas (10 $[0,2 \%])$ e doenças nutricionais $(6[0,1 \%])$. Outros distúrbios, que incluem doenças multifatoriais ou idiopáticas, contribuíram com $80(1,6 \%)$ casos. Dos 4.844 casos, em 1.548 $(32,0 \%)$ não foi possível estabelecer a causa da morte ou a razão para a eutanásia. Doenças infecciosas e parasitárias (principalmente cinomose, parvovirose e verminose intestinal), neoplasmas (principalmente neoplasmas mamários e linfoma), distúrbios causados por agentes físicos (principalmente atropelamento por veículos automotivos) e doenças degenerativas (principalmente insuficiência renal crônica, cirrose e insuficiência cardíaca congestiva) foram as principais categorias de doenças relacionadas com morte ou eutanásia de cães dessa mesorregião. Entretanto, quando os cães são avaliados de acordo com suas idades, tais categorias possuem prevalências diferentes. As principais causas de morte em filhotes foram as doenças infecciosas e parasitárias, principalmente parvovirose, cinomose e verminose intestinal. Em adultos, as causas de morte mais importantes foram cinomose, neoplasmas e trauma. Em idosos, neoplasmas e doenças degenerativas foram responsáveis por aproximadamente a metade das mortes.

TERMOS DE INDEXAÇÃO: Doenças de cães, causas de morte, razões para eutanásia.

\section{INTRODUÇÃO}

O estudo sobre mortalidade em cães promove informações úteis em vários aspectos e, portanto, tem amplas aplicações (Bonnett et al. 2005). Do ponto de vista veterinário é interessante conhecer as principais causas de morte e também é relevante estar consciente de suas diferenças entre as raças, o sexo, o porte ou a idade para poder aconselhar futuros proprietários de cães sobre medidas de saúde que possam minimizar ou pelo menos retardar o aparecimento de determinadas doenças mais comuns (Proschowsky et al. 2003). Comparando semeIhanças e diferenças nos padrões de mortalidade de de- terminadas espécies, raças, portes e idades, pode-se sugerir teorias sobre causas de doenças, o que inclusive permite estudar determinadas populações animais como modelos para doenças humanas (Bonnett et al. 2005). Além disso, o conhecimento sobre a prevalência das diferentes doenças que afetam determinadas populações de cães serve como um guia na hora de se estabelecer a lista de diagnósticos diferenciais frente à determinada manifestação clínica, laboratorial ou anatomopatológica.

A palavra mortalidade pode ser encontrada no título de numerosos artigos sobre cães na literatura veterinária, entretanto, quase a totalidade desses artigos descreve uma proporção de mortes em uma série de casos sobre uma doença específica (Martin 1987). Estudos epidemiológicos abrangentes sobre causas de morte e razões para eutanásia em cães são escassos, provavelmente devido à dificuldade em obter-se dados confiáveis. Os poucos artigos disponíveis na literatura quase sempre têm como finalidade principal definir a longevidade de cães de acordo com a raça ou sexo (Bronson 1982, Eichelberg \& Seine 1996, Bonnett et al. 1997, 2005, Patronek et al. 1997, Hayashidani et al. 1998, Michell 1999, Egenvall et al. 2000, Moore et al. 2001, Proschowsky et al. 2003, Egenvall et al. 2005). No entanto, como quase sempre esses estudos são realizados com prontuários de atendimento clínico ou com protocolos de necropsia, dados sobre causas de morte são disponibilizados pelos autores e utilizados para estabelecer as doenças que mais comumente levam certas raças à morte.

Baseado no fato de que na mesorregião do Centro Ocidental Rio-Grandense não há nenhum parâmetro epidemiológico sobre mortalidade em cães, esse estudo tem como objetivo determinar a prevalência das doenças que culminam em morte ou que fazem com que os cães dessa mesorregião sejam submetidos à eutanásia, dando ênfase à faixa etária em que normalmente ocorrem (filhotes, adultos ou idosos).

\section{MATERIAL E MÉTODOS}

Foram revisados todos os protocolos de necropsia de cães, arquivados no Laboratório de Patologia Veterinária (LPV) da Universidade Federal de Santa Maria (UFSM), realizadas entre janeiro de 1965 e dezembro de 2004 (40 anos). Foram incluídos neste estudo somente os cães oriundos de municípios que compõem a mesorregião do Centro Ocidental Rio-Grandense. São eles: Agudo, Cacequi, Capão do Cipó, Dilermando de Aguiar, Dona Francisca, Faxinal do Soturno, Formigueiro, Itaara, Itacurubi, Ivorá, Jaguari, Jari, Júlio de Castilhos, Mata, Nova Esperança do Sul, Nova Palma, Pinhal Grande, Quevedos, Restinga Seca, Santa Maria, Santiago, São João do Polêsine, São Martinho da Serra, São Pedro do Sul, São Sepé, São Vicente do Sul, Silveira Martins, Toropi, Tupanciretã, Unistalda e Vila Nova do Sul. A escolha das informações coletadas dos protocolos baseou-se em um estudo semelhante (Moore et al. 2001). Embora muitos cães tivessem mais do que um processo patológico, um único diagnóstico definitivo foi estabelecido para cada caso, à semelhança do que foi feito em outros estudos (Bonnett et al. 1997, 2005, Moore et al. 2001). Quando as evi- 
dências não permitiam estabelecer um diagnóstico definitivo, os casos foram considerados inconclusivos. Tais situações estavam associadas à ausência completa de lesões morfológicas ou à presença apenas de lesões incidentais. Foram também considerados como inconclusivos todos os casos em que, embora houvesse suspeita clínica de intoxicação, não fora realizado exame toxicológico.

As doenças que causaram a morte espontânea dos cães ou que foram responsáveis pela eutanásia foram convenientemente agrupadas em: distúrbios causados por agentes físicos, distúrbios do desenvolvimento, distúrbios iatrogênicos, doenças degenerativas, doenças imunomediadas, doenças infecciosas e parasitárias, doenças metabólicas e endocrinológicas, doenças nutricionais, intoxicações e toxiinfecções e neoplasmas. As doenças que não puderam ser classificadas em nenhum desses tópicos foram agrupadas sob a expressão "outros distúrbios", semelhantemente ao que foi feito em outros estudos (Moore et al. 2001, Proschowsky et al. 2003). Os cães submetidos à eutanásia sem apresentar uma doença clínica que justificasse tal procedimento foram incluídos em um grupo denominado "eutanásia por conveniência". Após essa classificação foi calculada a prevalência de cada grupo e de cada condição em relação ao total de animais necropsiados.

Os cães foram subdivididos em três grandes grupos etários: filhotes (até um ano de idade), adultos (de um a nove anos de idade) e idosos (dez anos de idade ou mais). Os limites de cada faixa etária foram estipulados por uma média dos valores reconhecidos internacionalmente para cada porte de cão (Goldston \& Hoskins 1999). Essa média se fez necessária porque o porte dos cães sem raça definida deste estudo não pôde ser determinado através dos protocolos de necropsia.

Não foram revisados os aspectos macroscópicos ou histológicos que levaram a um determinado diagnóstico definitivo; os principais motivos para essa conduta são os seguintes: 1) em muitos casos não havia mais material arquivado (lâminas, material em formol ou blocos de parafina), 2) seria necessário muito tempo e se despenderia muito dinheiro e 3) os diagnósticos finais das entidades são, na sua grande maioria, fruto da interpretação individual de patologistas experientes e não haveria motivo para questionar o diagnóstico original.

\section{RESULTADOS}

Nos arquivos do Laboratório de Patologia Veterinária (LPV) da Universidade Federal de Santa Maria (UFSM), no período entre janeiro de 1965 e dezembro de 2004, foram encontrados 4.844 protocolos de necropsia de cães. Desses, $56,4 \%$ correspondiam a machos e $43,6 \%$ a fêmeas. Do total de cães, 39,0\% foram incluídos como fiIhotes, $48,6 \%$ como adultos e $12,4 \%$ como idosos.

Dos 4.844 protocolos de necropsia de cães, em 3.296 $(68,0 \%)$ foi possível estabelecer a doença que causou a morte ou que levou o cão a ser submetido à eutanásia. Esses casos foram por nós denominados conclusivos. Em $1.548(32,0 \%)$ protocolos avaliados não foram encontradas evidências suficientes para se estabelecer um diagnóstico definitivo. Esses casos foram por nós denominados inconclusivos.

Os 3.296 casos conclusivos distribuíram-se em relação a categorias de doenças diagnosticadas da seguinte forma, em ordem decrescente de prevalência: doenças infecciosas e parasitárias, neoplasmas, distúrbios causados por agentes físicos, doenças degenerativas, intoxicações e toxiinfecções, eutanásia por conveniência, doenças metabólicas e endocrinológicas, distúrbios iatrogênicos, distúrbios do desenvolvimento, doenças imunomediadas e doenças nutricionais. A prevalência geral e por faixa etária dos casos em relação às categorias de doenças pode ser contemplada no Quadro 1.

Dos 4.844 casos, em 1.693 (35,0\%) os cães morreram ou foram submetidos à eutanásia por apresentarem algum tipo de doença infecciosa ou parasitária. Dentre essas, a cinomose, a parvovirose, a verminose intestinal e a leptospirose foram as mais prevalentes. Outras doenças infecciosas freqüentemente diagnosticadas incluíram: pneumonia bacteriana, raiva, endocardite valvar bacteriana, hepatite infecciosa canina e toxoplasmose.

Em 378 dos 4.844 (7,8\%) casos, os cães morreram ou foram submetidos à eutanásia por apresentarem complicações relacionadas a neoplasmas. Em 321 (84,9\%) casos, foi possível estabelecer um sítio primário para o neoplasma (apresentação não-multicêntrica). Em 57 $(15,1 \%)$ casos, havia múltiplos tumores malignos disseminados pelo corpo (apresentação multicêntrica). Os principais neoplasmas diagnosticados incluíram, em ordem decrescente de freqüência: neoplasmas malignos mamá-

Quadro 1. Prevalência das categorias de doenças diagnosticadas por faixa etária em cães necropsiados no LPV-UFSM de 1965-2004

\begin{tabular}{lcccc}
\hline \multicolumn{1}{c}{ Categoria de doença } & Filhote(\%) & Adulto(\%) & Idoso(\%) & Geral(\%) \\
\hline Doenças infecciosas e parasitárias & 55,3 & 27,5 & 12,4 & 35,0 \\
Neoplasmas & - & 7,9 & 32,0 & 7,8 \\
Distúrbios causados por agentes físicos & 6,4 & 9,0 & 4,1 & 7,6 \\
Doenças degenerativas & 0,6 & 8,3 & 22,6 & 7,1 \\
Intoxicações e toxiinfecções & 1,0 & 3,5 & 1,5 & 2,3 \\
Eutanásia por conveniência & 1,0 & 1,7 & 3,3 & 2,1 \\
Doenças metabólicas e endocrinológicas & 0,1 & 2,9 & 5,0 & 2,0 \\
Distúrbios iatrogênicos & 1,3 & 1,4 & 2,0 & 1,7 \\
Distúrbios do desenvolvimento & 1,2 & 0,2 & - & 0,5 \\
Doenças imunomediadas & 0,1 & 0,3 & - & 0,2 \\
Doenças nutricionais & 0,4 & - & - & 0,1 \\
Outros distúrbios & 0,3 & 2,6 & - & 1,6 \\
Inconclusivos & 32,0 & 34,5 & 14,1 & 32,0
\end{tabular}

Pesq. Vet. Bras. 28(4):223-230, abril 2008 
rios, linfoma multicêntrico, osteossarcoma esquelético, colangiocarcinoma, mastocitoma cutâneo, hemangiossarcoma multicêntrico e carcinoma renal.

Do total de casos, em 369 (7,6\%) os cães morreram ou foram submetidos à eutanásia por apresentarem distúrbios causados por agentes físicos. Dentre esses, os traumas e as obstruções gastrintestinais foram os mais prevalentes. Dos casos em que foi possível estabelecer as causas dos traumas, essas incluíram principalmente atropelamento por veículos automotivos, agressão por humanos e brigas entre cães. Obstruções gastrintestinais foram observadas em conseqüência de ingestão de corpos estranhos, intussuscepção, torção de intestino ou fecaloma.

Dos 4.844 casos, em $342(7,1 \%)$ os cães morreram ou foram submetidos à eutanásia por apresentarem algum tipo de doença degenerativa. Dentre essas, a insuficiência renal crônica, a cirrose, a insuficiência cardíaca congestiva e a doença do disco intervertebral foram as mais prevalentes.

Em 112 dos 4.844 (2,3\%) casos, os cães morreram ou foram submetidos à eutanásia por apresentarem intoxicações ou toxiinfecções. Dentre as intoxicações, a intoxicação por estricnina foi a mais freqüentemente diagnosticada. Casos de insuficiência renal aguda (por nefrotoxicidade) e aflatoxicose também foram relativamente comuns.

Do total de casos, em 101 (2,1\%) os cães foram submetidos à eutanásia por conveniência. Nesses casos, a eutanásia foi motivada por diferentes situações, que foram classificadas como: lesões traumáticas com possibilidade de tratamento clínico-cirúrgico, lesões crônicas de pele, motivo fútil (não associado à doença) e neoplasmas benignos.

Dos 4.844 casos, em 97 (2,0\%) os cães morreram ou foram eutanasiados por apresentarem algum tipo de doença metabólica ou endocrinológica. Dentre essas, o complexo hiperplasia endometrial cística/piometra foi a entidade clinicopatológica mais comum.

Em 83 dos 4.844 (1,7\%) casos, havia sólidas evidências de que os cães tinham morrido em decorrência de algum distúrbio iatrogênico. Na maioria desses casos, os cães haviam sofrido procedimentos cirúrgicos eletivos. As

Quadro 2. Distribuição das diferentes doenças diagnosticadas em cães necropsiados no LPV-UFSM de 1965-2004

\begin{tabular}{|c|c|c|c|c|c|}
\hline $\begin{array}{l}\text { Causa da morte ou } \\
\text { razão para eutanásia }\end{array}$ & Total & $\%$ & $\begin{array}{l}\text { Causa da morte ou } \\
\text { razão para eutanásia }\end{array}$ & Total & $\%$ ra \\
\hline Cinomose & 602 & 12,4 & Cistite com ruptura de bexiga & 8 & 0,2 \\
\hline Neoplasmas & 378 & 7,8 & Pielonefrite & 8 & 0,2 \\
\hline Parvovirose & 351 & 7,2 & Choque neurogênico & 7 & 0,1 \\
\hline Traumas & 276 & 5,7 & Epilepsia idiopática & 7 & 0,1 \\
\hline Verminose intestinal & 162 & 3,3 & Acidente com abelhas & 6 & 0,1 \\
\hline Insuficiência renal crônica & 115 & 2,4 & Asfixia & 6 & 0,1 \\
\hline Leptospirose & 108 & 2,2 & Osteodistrofia fibrosa nutricional & 5 & 0,1 \\
\hline Pneumonia bacteriana & 105 & 2,2 & Espondilite & 4 & $<0,1$ \\
\hline Eutanásia por conveniência & 101 & 2,1 & Intoxicação por carbamato & 4 & $<0,1$ \\
\hline Raiva & 91 & 1,9 & Ofidismo & 4 & $<0,1$ \\
\hline Obstrução gastrintestinal & 87 & 1,8 & Tétano & 4 & $<0,1$ \\
\hline Distúrbios iatrogênicos & 83 & 1,7 & Tuberculose & 4 & $<0,1$ \\
\hline Cirrose & 78 & 1,6 & Anafilaxia & 3 & $<0,1$ \\
\hline Endocardite valvar bacteriana & 72 & 1,5 & Diabete melito & 3 & $<0,1$ \\
\hline Insuficiência cardíaca congestiva & 72 & 1,5 & Meningoencefalite granulomatosa & 3 & $<0,1$ \\
\hline Complexo HECa/piometra & 61 & 1,2 & Pitiose & 3 & $<0,1$ \\
\hline Intoxicação por estricnina & 60 & 1,2 & Botulismo & 2 & $<0,1$ \\
\hline Hepatite infecciosa canina & 49 & 1,0 & Eclampsia & 2 & $<0,1$ \\
\hline Toxoplasmose & 47 & 1,0 & Enterite por Isospora canis & 2 & $<0,1$ \\
\hline Doença do disco intervertebral & 43 & 0,9 & MMM $^{\mathrm{b}}$ & 2 & $<0,1$ \\
\hline Dilatação-vólvulo gástrico & 34 & 0,7 & Aspergilose sistêmica & 1 & $<0,1$ \\
\hline Urolitíase & 31 & 0,6 & Candidíase sistêmica & 1 & $<0,1$ \\
\hline Endometrite pós-parto & 27 & 0,6 & Doença eosinofílica disseminada & 1 & $<0,1$ \\
\hline Distúrbios do desenvolvimento & 25 & 0,5 & Intoxicação por estrogênio & 1 & $<0,1$ \\
\hline Rangeliose & 19 & 0,4 & Intoxicação por ivermectina & 1 & $<0,1$ \\
\hline Insuficiência renal aguda & 17 & 0,4 & Linfangiectasia & 1 & $<0,1$ \\
\hline Pancreatite aguda & 17 & 0,4 & Mastite bacteriana & 1 & $<0,1$ \\
\hline Piotórax & 16 & 0,3 & Meningite bacteriana & 1 & $<0,1$ \\
\hline Distocia & 13 & 0,3 & Raquitismo & 1 & $<0,1$ \\
\hline Aflatoxicose & 13 & 0,3 & Traquéia colapsada & 1 & $<0,1$ \\
\hline Hérnia perineal encarcerada & 13 & 0,3 & Vasculite meníngea & 1 & $<0,1$ \\
\hline Displasia coxofemural & 11 & 0,2 & Inconclusivo & 1.548 & 32,0 \\
\hline Gastrenterite hemorrágica ${ }^{c}$ & 11 & 0,2 & & & \\
\hline Espondilose deformante & 10 & 0,2 & Total & 4.844 & - \\
\hline
\end{tabular}


complicações que levaram esses cães à morte incluíram principalmente depressão anestésica, peritonite e hemorragia pós-cirúrgica. Alterações relacionadas a intervenções clínicas ocorreram em menor quantidade e incluíram casos de ulceração gástrica induzida por fármacos, principalmente antiinflamatórios não-esteroidais, e miosite bacteriana pós-injeção.

O restante dos 4.844 casos foi categorizado em distúrbios do desenvolvimento (25 [0,5\%]), doenças imunomediadas $(10[0,2 \%])$ e doenças nutricionais $(6[0,1 \%])$. "Outros distúrbios" totalizaram $80(1,6 \%)$ casos.

A distribuição das diferentes doenças diagnosticadas em cães no LPV-UFSM entre 1965-2004 pode ser contemplada no Quadro 2. Essa distribuição pode também ser vista de acordo com cada faixa etária, ou seja, adultos, filhotes e idosos, nos Quadros 3-5, respectivamente.

\section{DISCUSSÃO}

Dos 4.844 cães necropsiados, mais de um terço $(35,0 \%)$ morreram em decorrência de doenças infecciosas ou parasitárias. Com exceção de um estudo conduzido no su- deste do Brasil (Bentubo et al. 2007), que mostrou prevalência semelhante $(37,1 \%)$, todos os estudos disponíveis (Bonnett et al. 1997, 2005, Craig 2001, Moore et al. 2001, Proschowsky et al. 2003) resultaram em baixa prevalência de doenças infecciosas ou parasitárias como causa de morte de cães.

Acredita-se que a alta prevalência das doenças infecciosas e parasitárias como causa de morte de cães constatada neste estudo e também em outro estudo brasileiro (Bentubo et al. 2007) esteja relacionada à baixa adesão aos programas de vacinação e everminação, já que ainda hoje no Brasil apenas uma pequena parcela de proprietários adere a esquemas de vacinação e everminação completos para seus cães, ao contrário do que ocorre nos Estados Unidos e na Europa, onde a maior parte dos cães é vacinada e revacinada anualmente (Greene \& Schultz 2006).

Dos 4.844 cães necropsiados, 7,8\% morreram ou foram submetidos à eutanásia por apresentarem complicações relacionadas a neoplasmas. Essa prevalência está abaixo da variação mundialmente reconhecida para ani-

\section{Quadro 3. Distribuição das diferentes doenças diagnosticadas em cães adultos} necropsiados no LPV-UFSM de 1965-2004

\begin{tabular}{|c|c|c|c|c|c|}
\hline $\begin{array}{l}\text { Causa da morte ou } \\
\text { razão para eutanásia }\end{array}$ & Total & $\%$ & $\begin{array}{l}\text { Causa da morte ou } \\
\text { razão para eutanásia }\end{array}$ & Total & $\%$ \\
\hline Cinomose & 261 & 12,3 & Epilepsia idiopática & 6 & 0,3 \\
\hline Neoplasmas & 168 & 7,9 & Asfixia & 5 & 0,2 \\
\hline Traumas & 153 & 7,2 & Choque neurogênico & 5 & 0,2 \\
\hline Insuficiência renal crônica & 64 & 3,0 & Espondilose deformante & 5 & 0,2 \\
\hline Leptospirose & 58 & 2,7 & Distúrbios do desenvolvimento & 4 & 0,2 \\
\hline Raiva & 53 & 2,5 & Hérnia perineal encarcerada & 4 & 0,2 \\
\hline Intoxicação por estricnina & 41 & 1,9 & Espondilite & 4 & 0,2 \\
\hline Complexo HECa/piometra & 40 & 1,9 & Ofidismo & 4 & 0,2 \\
\hline Eutanásia por conveniência & 37 & 1,7 & Pielonefrite & 4 & 0,2 \\
\hline Endocardite valvar bacteriana & 36 & 1,7 & Acidente com abelhas & 3 & 0,1 \\
\hline Cirrose & 35 & 1,6 & Intoxicação por carbamato & 3 & 0,1 \\
\hline Doença do disco intervertebral & 34 & 1,6 & Meningoencefalite granulomatosa & 3 & 0,1 \\
\hline Obstrução gastrintestinal & 33 & 1,6 & Pitiose & 3 & 0,1 \\
\hline Distúrbios iatrogênicos & 31 & 1,4 & Anafilaxia & 2 & $<0,1$ \\
\hline Pneumonia bacteriana & 31 & 1,4 & Diabete melito & 2 & $<0,1$ \\
\hline Insuficiência cardíaca congestiva & 28 & 1,3 & Eclampsia & 2 & $<0,1$ \\
\hline Parvovirose & 25 & 1,2 & Tuberculose & 2 & $<0,1$ \\
\hline Dilatação-vólvulo gástrico & 20 & 0,9 & Aspergilose sistêmica & 1 & $<0,1$ \\
\hline Endometrite pós-parto & 19 & 0,9 & Botulismo & 1 & $<0,1$ \\
\hline Toxoplasmose & 18 & 0,8 & Doença eosinofílica disseminada & 1 & $<0,1$ \\
\hline Urolitíase & 18 & 0,8 & Intoxicação por estrogênio & 1 & $<0,1$ \\
\hline Hepatite infecciosa canina & 16 & 0,8 & Intoxicação por ivermectina & 1 & $<0,1$ \\
\hline Verminose intestinal & 14 & 0,7 & Linfangiectasia & 1 & $<0,1$ \\
\hline Insuficiência renal aguda & 12 & 0,6 & Mastite bacteriana & 1 & $<0,1$ \\
\hline Distocia & 11 & 0,5 & Meningite bacteriana & 1 & $<0,1$ \\
\hline Pancreatite aguda & 11 & 0,5 & $\mathrm{MMM}^{\mathrm{b}}$ & 1 & $<0,1$ \\
\hline Rangeliose & 11 & 0,5 & Tétano & 1 & $<0,1$ \\
\hline Gastrenterite hemorrágica ${ }^{c}$ & 9 & 0,4 & Traquéia colapsada & 1 & $<0,1$ \\
\hline Piotórax & 9 & 0,4 & Vasculite meníngea & 1 & $<0,1$ \\
\hline Aflatoxicose & 8 & 0,4 & Inconclusivo & 734 & 34,5 \\
\hline Cistite com ruptura de bexiga & 8 & 0,4 & & & \\
\hline Displasia coxofemoral & 6 & 0,3 & Total & 2.125 & - \\
\hline
\end{tabular}


Quadro 4. Distribuição das diferentes doenças diagnosticadas em cães filhotes necropsiados no LPV-UFSM de 1965-2004

\begin{tabular}{lcclrr}
\hline $\begin{array}{c}\text { Causa da morte ou } \\
\text { razão para eutanásia }\end{array}$ & Total & $\%$ & $\begin{array}{c}\text { Causa da morte ou } \\
\text { razão para eutanásia }\end{array}$ & Total & $\%$ \\
\hline Parvovirose & 314 & 18,4 & Aflatoxicose & 3 & 0,2 \\
Cinomose & 293 & 17,2 & Dilatação-vólvulo gástrico & 3 & 0,2 \\
Verminose intestinal & 141 & 8,3 & Endocardite valvar bacteriana & 3 & 0,2 \\
Traumas & 69 & 4,0 & Enterite por Isospora canis & 2 & 0,1 \\
Pneumonia bacteriana & 63 & 3,7 & Insuficiência renal aguda & 2 & 0,1 \\
Obstrução gastrintestinal & 40 & 2,3 & Tétano & 2 & 0,1 \\
Leptospirose & 39 & 2,3 & Urolitíase & 2 & 0,1 \\
Hepatite infecciosa canina & 31 & 1,8 & Anafilaxia & 1 & $<0,1$ \\
Toxoplasmose & 24 & 1,4 & Asfixia & 1 & $<0,1$ \\
Distúrbios iatrogênicos & 23 & 1,3 & Choque neurogênico & 1 & $<0,1$ \\
Distúrbios do desenvolvimento & 21 & 1,2 & Cirrose & 1 & $<0,1$ \\
Raiva & 19 & 1,1 & Doença do disco intervertebral & 1 & $<0,1$ \\
Eutanásia por conveniência & 17 & 1,0 & Epilepsia idiopática & 1 & $<0,1$ \\
Intoxicação por estricnina & 8 & 0,5 & Gastrenterite hemorrágica & 1 & $<0,1$ \\
Rangeliose & 6 & 0,4 & MMM & 1 & $<0,1$ \\
Insuficiência cardíaca congestiva & 5 & 0,3 & Pielonefrite & 1 & $<0,1$ \\
Osteodistrofia fibrosa nutricional & 5 & 0,3 & Raquitismo & 1 & $<0,1$ \\
Piotórax & 5 & 0,3 & Tuberculose & 1 & $<0,1$ \\
Insuficiência renal crônica & 4 & 0,2 & Inconclusivo & 546 & 32,0 \\
Acidente com abelhas & 3 & 0,2 & Total & 1.704 & -
\end{tabular}

a MMM = Miosite dos músculos mastigatórios.

Quadro 5. Distribuição das diferentes doenças diagnosticadas em cães idosos necropsiados no LPV-UFSM de 1965-2004

\begin{tabular}{lccllcr}
\hline \multicolumn{1}{c}{$\begin{array}{c}\text { Causa da morte ou } \\
\text { razão para eutanásia }\end{array}$} & Total & $\%$ & \multicolumn{1}{c}{$\begin{array}{c}\text { Causa da morte ou } \\
\text { razão para eutanásia }\end{array}$} & Total & $\%$ \\
\hline Neoplasmas & 173 & 32,0 & Endometrite pós-parto & 4 & 0,7 \\
Cirrose & 36 & 6,7 & Intoxicação por estricnina & 4 & 0,7 \\
Insuficiência cardíaca congestiva & 34 & 6,3 & Espondilose deformante & 3 & 0,6 \\
Endocardite valvar bacteriana & 33 & 6,1 & Insuficiência renal aguda & 2 & 0,4 \\
Insuficiência renal crônica & 33 & 6,1 & Pneumonia bacteriana & 2 & 0,4 \\
Complexo HECa/piometra & 19 & 3,5 & Aflatoxicose & 1 & 0,2 \\
Eutanásia por conveniência & 18 & 3,3 & Botulismo & 1 & 0,2 \\
Cinomose & 15 & 2,8 & Candidíase sistêmica & 1 & 0,2 \\
Traumas & 14 & 2,6 & Distocia & 1 & 0,2 \\
Distúrbios iatrogênicos & 11 & 2,0 & Gastrenterite hemorrágicab & 1 & 0,2 \\
Dilatação-vólvulo gástrico & 10 & 1,8 & Pielonefrite & 1 & 0,2 \\
Obstrução gastrintestinal & 8 & 1,5 & Raiva & 1 & 0,2 \\
Urolitíase & 8 & 1,5 & Rangeliose & 1 & 0,2 \\
Doença do disco intervertebral & 6 & 1,1 & Toxoplasmose & 1 & 0,2 \\
Hérnia perineal encarcerada & 6 & 1,1 & Tuberculose & 1 & 0,2 \\
Leptospirose & 6 & 1,1 & Inconclusivo & 76 & 14,1 \\
Pancreatite aguda & 5 & 0,9 & Total & 540 & - \\
Displasia coxofemural & 4 & 0,7 & Tola
\end{tabular}

mais de companhia (16,0\% a 24,0\%) (Weller 2004), abaixo dos resultados observados em outra região do Brasil $(13,3 \%)$ (Bentubo et al. 2007) e é bem inferior aos resultados obtidos em estudos realizados nos Estados Unidos e na Europa. Nos Estados Unidos, neoplasmas foram incriminados como causa de morte ou razão para eutanásia em 18,3\% (Moore et al. 2001), 39,0\% (Bronson 1982) e $39,5 \%$ (Craig 2001) dos cães. Na Europa, neoplasmas foram considerados como responsáveis pela morte ou eutanásia de 16,0\% a 18,0\% dos cães suecos (Bonnett et al. 1997, 2005), 15,7\% dos cães ingleses (Michell 1999) e
$14,5 \%$ dos cães dinamarqueses (Proschowsky et al. 2003).

Segundo muitos autores (Bonnett et al. 1997, 2005, Craig 2001, Moore et al. 2001, Proschowsky et al. 2003), essa prevalência acentuadamente alta de neoplasmas em cães norte-americanos e europeus deve-se ao fato desses terem atualmente uma expectativa de vida muito maior do que anos atrás. Dessa forma, a menor expectativa de vida dos cães em nosso país (Bentubo et al. 2007) talvez contribua para a essa menor prevalência de neoplasmas como causa da morte de cães em nossa 
mesorregião. Entretanto, acreditamos que parte dessa menor prevalência seja decorrente da alta prevalência de mortes atribuídas a doenças infecciosas, o que acaba distorcendo a proporção exata das mortes associadas a neoplasmas.

Dos 4.844 cães necropsiados, 5,7\% morreram ou foram submetidos à eutanásia em decorrência de trauma, um resultado semelhante ao observado na Inglaterra $(4,9 \%)$ (Michell 1999) e na Dinamarca $(6,1 \%)$ (Proschowsky et al. 2003), mas diferente do encontrado nos Estados Unidos (1,0\%-3,5\%) (Craig 2001, Moore et al. 2001) e na Suécia (16,2\%-17,0\%) (Bonnett et al. 1997, 2005). No que se refere às causas mais comuns de trauma, fazendo uma comparação direta entre os resultados deste estudo e aqueles observados em cães suecos e norte-americanos, pode-se perceber que a percentagem de cães atropelados por veículos automotivos foi relativamente semelhante. Entretanto, a segunda causa de trauma mais comum em nossa mesorregião (agressão por humanos) não é sequer citada em qualquer estudo sobre causas de morte de cães.

Dos 4.844 cães necropsiados, 2,3\% morreram ou foram submetidos à eutanásia em decorrência de intoxicações ou toxiinfecções, uma prevalência bem menor do que a descrita em um artigo nacional recente (Bentubo et al. 2007). Entretanto, deve-se ressaltar que nesse estudo (Bentubo et al. 2007) não está explícito como os diagnósticos foram confirmados. Na maioria dos artigos internacionais sobre causas de morte em cães não há menção de casos de intoxicação. Em um estudo sobre morte súbita realizado no Canadá (Olsen \& Allen 2000), 16,6\% dos cães morreram por algum tipo de intoxicação. Essa prevalência é bem maior do que a observada neste estudo, entretanto, comparações são difíceis porque a população geral de cães mortos nos dois estudos é muito diferente.

Distúrbios iatrogênicos perfizeram $1,7 \%$ de todas as mortes neste estudo e não são sequer citados em nenhum artigo sobre causa de morte disponível na literatura. Em um estudo realizado com cães militares nos Estados Unidos (Moore et al. 2001), 1,1\% dos cães morreram durante a anestesia, uma prevalência semelhante à observada aqui ( $0,7 \%$ do total de cães deste estudo). Além de depressão anestésica, houve muitos casos de alterações relacionadas a intervenções cirúrgicas, como peritonite e hemorragia pós-cirúrgica. Essa alta prevalência de casos iatrogênicos não se deve apenas a problemas cirúrgicos, mas também a alterações relacionadas a intervenções clínicas, principalmente pelo uso indiscriminado do antiinflamatório não-esteroidal diclofenaco sódico e potássico, uma droga reconhecidamente ulcerogênica para cães (Corrêa et al. 1997), mas que no passado era recomendada por alguns farmacologistas veterinários (Tasaka 1996) e ainda hoje é utilizada indiscriminadamente por muitos clínicos, criadores e, principalmente, proprietários.

Com base resultados observados neste estudo podese observar que há algumas semelhanças e muitas dife- renças quando se comparam as causas de morte entre filhotes, adultos e idosos. Embora doenças infecciosas e parasitárias tenham sido a principal causa de óbito em filhotes e adultos, sua prevalência em relação ao total de cães necropsiados foi bem diferente nessas duas categorias etárias $(55,3 \%$ versus $27,5 \%)$.

As principais doenças infecciosas que afetaram filhotes, adultos e idosos têm prevalência totalmente diferente como causa de morte. Parvovirose, por exemplo, foi a principal doença diagnosticada em filhotes neste estudo, com uma prevalência de $18,4 \%$. Essa doença, no entanto, contribuiu com apenas $1,2 \%$ dos óbitos em adultos. Cinomose foi a doença mais diagnosticada em adultos $(12,3 \%)$ e a segunda doença mais prevalente em filhotes $(17,2 \%)$, mas ocorreu com baixa freqüência em idosos $(2,8 \%)$. Cinomose é considerada uma doença que afeta principalmente filhotes entre três e seis meses de idade (Lappin 2001, Greene \& Appel 2006). Embora esse seja um dado clínico e não de necropsia, se considerarmos que grande parte dos cães com essa doença morre espontaneamente ou é submetida à eutanásia, seria de se esperar que cinomose tivesse uma relação filhote:adulto bem maior. Embora não se conheça a população sob risco para avaliar se a doença foi realmente mais freqüente em filhote, a alta prevalência em cães adultos demonstra que cinomose é também muito comum nessa faixa etária em cães dessa mesorregião.

Neoplasmas tiveram a maior variação entre as categorias etárias, pois foram a principal causa de morte em idosos $(32,0 \%)$, a quarta categoria mais importante em adultos $(7,9 \%)$ e não causaram morte de filhotes. Doenças degenerativas, à semelhança do que ocorreu com os neoplasmas, também tiveram grande variação etária. As três principais doenças degenerativas (insuficiência renal crônica, cirrose e insuficiência cardíaca congestiva) tiveram variações semelhantes e diretamente proporcionais em relação às categorias etárias.

\section{CONCLUSÕES}

Os resultados deste estudo permitem concluir que as principais causas de morte (incluindo eutanásia) de cães na mesorregião do Centro Ocidental Rio-Grandense são cinomose, neoplasmas, parvovirose, trauma e verminose intestinal. Entretanto, quando os cães são avaliados de acordo com suas idades, tais causas possuem prevalências diferentes. As principais causas de morte em filhotes apontadas por este estudo são as doenças infecciosas e parasitárias, principalmente parvovirose, cinomose e verminose intestinal. Em adultos, as causas de morte mais importantes são cinomose, neoplasmas e trauma. Em idosos, neoplasmas e doenças degenerativas são responsáveis por aproximadamente a metade das mortes.

Tanto em cães adultos como em idosos, as doenças degenerativas mais relacionadas à morte incluem insuficiência renal crônica, cirrose e insuficiência cardíaca congestiva decorrente de insuficiência valvar por endocardiose ou de miocardiopatias primárias. Dentre os neo- 
plasmas que causam morte de cães, aqueles que se originam das glândulas mamárias constituem a maior parcela. Outros neoplasmas que comumente levam cães à morte incluem linfoma, colangiocarcinoma, osteossarcoma esquelético e mastocitoma cutâneo. Independentemente da faixa etária, as causas de trauma que mais freqüentemente são associadas à morte de cães são o atropelamento por veículos automotivos, a agressão por humanos e as brigas entre cães.

\section{REFERÊNCIAS}

Bentubo H.D.L., Tomaz M.A., Bondan E.F. \& Lallo M.A. 2007. Expectativa de vida e causas de morte em cães na área metropolitana de São Paulo (Brasil). Ciência Rural 37:1021-1026.

Bonnett B.N., Egenvall A., Olson P. \& Hedhammar A. 1997. Mortality in insured Swedish dogs: rates and causes of death in various breeds. Vet. Rec. 141:40-44.

Bonnett B.N., Egenvall A., Hedhammar A. \& Olson P. 2005. Mortality in over 350,000 insured Swedish dogs from 1995-2000: I. Breed-, gender-, age- and cause-specific rates. Acta Vet. Scand. 46:105-120.

Bronson R.T. 1982. Variation in age at death of dogs of different sexes and breeds. Am. J. Vet. Res. 43:2057-2059.

Correa V.P., Stopiglia A.J. \& Matushima E.R. 1997. Alterações gastrintestinais em cães com a utilização do diclofenaco sódico. Clin. Vet. 2:18-20.

Craig L.E. 2001. Cause of death in dogs according to breed: A necropsy survey of five breeds. J. Am. Anim. Hosp. Assoc. 37:438-443.

Edney A.T.B. 1998. Reasons for the euthanasia of dogs and cats. Vet. Rec. 143:114.

Egenvall A., Bonnett B.N., Shoukri M., Olson P., Hedhammar A. \& Dohoo I. 2000. Age pattern of mortality in eight breeds of insured dogs in Sweden. Prev. Vet. Med. 46:1-14.

Egenvall A., Bonnett B.N., Hedhammar A. \& Olson P. 2005. Mortality in over 350,000 insured Swedish dogs from 1995-2000: II. Breed-specific age and survival patterns and relative risk for causes of death. Acta Vet. Scand. 46:121-136.

Eichelberg H. \& Seine R. 1996. Life expectancy and cause of death in dogs. I. The situation in mixed breeds and various dog breeds. Berl. Münch. Tierärztl. Wochenschr. 109:292-303.

Goldston R.T. \& Hoskins J.D. 1999. Geriatria e gerontologia em cães e gatos. Roca, São Paulo. 551p.
Greene C.E. \& Appel M.J. 2006. Canine distemper, p.25-41. In: Greene C.E. (ed.), Infectious Diseases of the Dog and Cat. 3rd ed. Saunders Elsevier, St Louis. 1387p.

Greene C.E. \& Schultz R.D. 2006. Immunoprophylaxis, p.1069-1119. In: Greene C.E. (ed.), Infectious Diseases of the Dog and Cat. 3rd ed. Saunders Elsevier, St Louis. 1387p.

Hayashidani H., Omi Y., Ogawa M. \& Fukutomi K. 1998. Epidemiological studies on the expectation of life for dogs computed from animal cemetery records. Jpn. J. Vet. Sci. 50:1003-1008.

Kolata R.J., Kraut N.H. \& Johnston D.E. 1974. Patterns of trauma in urban dogs and cats: a study of 1,000 cases. J. Am. Vet. Med. Assoc. 164:499-502.

Lappin M.R. 2001. Doenças infecciosas, p.973-1053. In: Nelson R.W. \& Couto C.G. (ed.), Medicina Interna de Pequenos Animais. $2^{\underline{a}}$ ed. Guanabara Koogan, Rio de Janeiro. 1084p.

Martin S. 1987. Veterinary Epidemiology: Principles and methods. lowa State University Press, Ames.

Michell A.R. 1999. Longevity of British breeds of dog and its relationships with sex, size, cardiovascular variables and disease. Vet. Rec. 145:625629.

Moore G.E., Burkman K.D., Carten M.N. \& Peterson M.R. 2001. Causes of death or reasons for euthanasia in military working dogs: 927 cases (1993-1996). J. Am. Vet. Med. Assoc. 219:209-214.

Olsen T.F. \& Allen A.L. 2000. Causes of sudden and unexpected death in dogs: A 10-year retrospective study. Can. Vet. J. 41:873-875.

Patnaik A.K., Hurvitz A.I. \& Lieberman P.H. 1980. Canine hepatic neoplasms: A clinicopathologic study. Vet. Pathol. 17:553-564.

Patronek H.F., Waters D.J. \& Glickman L.T. 1997. Comparative longevity of pet dogs and humans: implications for gerontology research. J. Geront. 52:171-178.

Proschowsky H.F., Rugbjerg H. \& Ersbøll A.K. 2003. Mortality of purebred and mixed-breed dogs in Denmark. Prev. Vet. Med. 58:63-74.

Tasaka A.C. 1996. Antiinflamatórios não-esteroidais, p.195-207. In: Spinosa H.S., Górniak S.L. \& Bernardi M.M. (ed.), Farmacologia Aplicada à Medicina Veterinária. Guanabara Koogan, Rio de Janeiro. $545 p$.

Trigo F.J., Thompson H., Breeze R.G. \& Nash A.S. 1982. The pathology of liver tumours in the dog. J. Comp. Pathol. 92:21-39.

Weller R. 2004. Epidemiologia, etiologia e saúde pública, p.17-20. In: Rosenthal R.C. (ed.), Segredos em Oncologia Veterinária. Artmed, Porto Alegre. 295p. 